\title{
SOBRE UMA NÃO-TRADUÇÃO E ALGUMAS TRADUÇÕES DE "L'INVITATION AU VOYAGE" DE BAUDELAIRE Álvaro Faleiros
}

Je sais l'art d'évoquer les minutes heureuses! Charles Baudelaire

• (HARVEY, Vera Azambuja.

"Tradução e transcriação em Os gansos selvagens de Bassan", Cadernos do CEF no 3, Niterói, Centro de Estudos Francófonos da UFF, 1988: 117.)

"(Idem.)

( (lbidem.)
Sobre uma não-tradução de "L'invitation au voyage"

Vera de Azambuja Harvey, no artigo "Tradução e transcriação em Os gansos selvagens de Bassan", romance da escritora e poeta quebequense Anne Hébert, comenta que dentre os problemas de tradução com que se deparou ao longo da tradução, um dos mais "interessantes" foi o da intertextualidade. E o problema de intertextualidade mais complexo foi a tradução do seguinte fragmento do poema "Linvitation au voyage":

Tout y parlerait

À l'âme en secret

Sa douce langue natale.

Vera Harvey comenta que, no romance de Hébert, "a forma em verso não foi preservada e foi necessária uma leitura atenta para detectar esse recurso" na obra da autora quebequense." A tradutora assinala, em seguida, que fazia parte de seu horizonte de expectativas "também ter leitores atentos"; " motivo pelo qual, procurou "versos de um poeta brasileiro que se adequasse ao texto". A solução encontrada foi o seguinte trecho da "Canção do exílio" de Casimiro de Abreu:

Quero morrer cercado de perfumes

Dum clima tropical

E sentir expirando as harmonias

Do meu berço natal!

$\mathrm{Na}$ verdade, a associação feita foi entre "Lâme en secret/ sa douce langue natale" e "as harmonias/ do meu berço natal". A for- 
ma final que Vera Harvey adotou na sua tradução do romance é: "Minha mãe [...] fala-me em segredo das harmonias do meu berço natal'. Depois de apresentar a sua solução, em seu artigo, Vera Harvey não dá seguimento à discussão; satisfeita com o comentário aqui resumido.

Diante de tão inusitada escolha, justificada de forma tão ligeira, pareceu-me pertinente colocar a seguinte pergunta, formulada a partir de Jauss ${ }^{*}$ para pensar a relação entre o leitor e o texto: "Dada a premissa da mediação, qual é o horizonte de experiência histórica que o tradutor enquanto leitor traz para sua interpretação do original?"

Com efeito, como Vera Harvey assinala no título de seu artigo, ela parte de um princípio legítimo, bastante valorizado no Brasil, que é o princípio da transcriação. Como os irmãos Campos fizeram algumas vezes, ela desdobra as possibilidades intertextuais, deslocando as referências especificamente para dentro do sistema literário brasileiro. Assim, sua transfiguração de "L'invitation au voyage" leva a uma total devoração de Baudelaire, seguindo a melhor (ou pior) tradição antropofágica.

A primeira questão que se coloca dentro da lógica antropofágica ela mesma é: por que Casimiro de Abreu? O argumento avançado pela tradutora é de que ela "queria algo que fosse bem conhecido"; por isso optou por Casimiro. Entretanto, vale lembrar, este é o poeta que Antônio Cândido chama de "belo e doce". " Cândido também destaca que, em Casimiro: "Saudade, ternura, natureza e desejo são modulados numa frauta singela, sem a envergadura que assumem em Junqueira Freire, Álvares de Azevedo, mesmo Bernardo Guimarães".

A escolha de Vera Harvey é, pois, baseada exclusivamente num suposto grau de penetração e de importância da obra de Casimiro no sistema literário brasileiro. Suposição que, acredito, não se justifica, uma vez que Casimiro não tem nem a envergadura nem as marcas estéticas de Baudelaire. Curiosamente, Cândido também nos informa que Casimiro foi "o predileto dos cestos de costura, levando a um fervoroso público feminino toda a gama permitida de variaçōes em torno do enleio amoroso".

Se quiséssemos tentar uma aproximação de natureza temática, dentro da lógica da deglutição antropofágica, um caminho possível seria seguir as indicações de Jamir Almansur Haddad, que, ao comentar "L'invitation au voyage", assinala:
* (apud VIEIRA, Else. Teorizando e contextualizando a tradução. Belo Horizonte: FALE/UFMG, 1996: 115.)

"(MELLO E SOUSA, Antônio Cândido. Formação da literatura brasileira. 20 volume. Belo Horizonte/ Rio de Janeiro: Itatiaia, 1993: 173.)

(Idem.)

"(Idem.) 
(BAUDELAIRE, Charles. As flores do mal. Tradução Jamil Almansour Haddad. São Paulo: Max Limonad, 1981: 177.)

- (VIEIRA, Else. Teorizando e contextualizando a tradução. Op. cit.)

- (VIEIRA, Else. Teorizando e contextualizando a tradução. Op. cit.: 107.)

(Idem: 125.)
O tema deste poema, aliás, é extenso na poesia universal. No caso do Brasil pode reclamar aí sua filiação a Passárgada do poeta Manuel Bandeira. Péricles Eugênio da Silva Ramos chama um de seus poemas Invitation au voyage. Conferir também $A$ ilha de Cipango de Augusto dos Anjos, não obstante o fim pessimista do poema."

Não faltariam assim, poemas e poetas em que a temática fosse tratada de forma mais análoga do que em Casimiro de Abreu. De todo modo, caso se adotasse um desses outros (inter)textos, propostos por Haddad, as soluções continuariam dentro de um princípio, a meu ver, demasiadamente funcional: aquele que considera, em primeira instância, o efeito que um texto supostamente produz sobre o leitor.

Como assinala Else Vieira* ao comentar "a potencialidade da estética da recepção para a contextualização da tradução", o problema é que conceitos centrais, como o de "horizonte de expectativa", são colocados em termos nebulosos por autores como Jauss; e a ele se vincula outro grande problema desse tipo de abordagem, a saber, a dificuldade de se delinear os contornos de um leitor real. Retomando o princípio anunciado por Vera Harvey, ela arrisca trabalhar com um leitor modelo que remeteria preferencialmente a Casimiro de Abreu e não, por exemplo, a Augusto dos Anjos ou ao próprio Baudelaire. Assim, ao utilizar como critério a escolha de "algo que fosse bem conhecido" para ela, Vera Harvey levou à introdução de "doces e meigas" pétalas onde havia flores do mal.

\section{Da recepção ao poli-sistema literário}

Ao apontar os limites da estética da recepção para se pensar a tradução e o literário, Else Vieira* destaca a contribuição dos autores da escola de Tel-aviv, sobretudo a de Even-Zohar, que, ao invés de considerar o possível efeito do texto sobre o leitor, interessa-se pelo efeito da tradução sobre a dinâmica do sistema literário da língua-cultura de chegada. Else Vieira* informa que, para EvenZohar, a literatura traduzida deve ser considerada na sua conexão com a literatura original. Even-Zohar enfatiza o caráter dinâmico e heterogêneo dos sistemas, por isso chamados de poli-sistemas, nos quais estão imbricadas traduções, obras originais, outras formas de comentários, outras instâncias de controle e de legitimação. $\mathrm{O}$ caráter complexo dos sistemas também se dá pela existência de hierarquias culturais, ou seja, pelas relações dialéticas entre centro e periferia. 
A existência dessa rede múltipla, acredito, evidencia que, no momento de se fazer uma escolha tradutória, é importante perguntar-se sobre o papel e o lugar de um determinado autor estrangeiro no sistema literário de chegada. No Brasil, como se sabe, os efeitos das traduçōes e, para retomar Glória Carneiro do Amaral, também os efeitos das aclimataçôes de Baudelaire, são altamente produtivos na configuração do sistema literário brasileiro.

Desde o artigo de Machado de Assis, de 1879, multiplicaramse as reflexões e os mapeamentos da influência literária de Baudelaire no Brasil. Como assinala Antônio Cândido, nos anos de 1870 e começo dos de 1880, "a presença de Baudelaire foi decisiva para

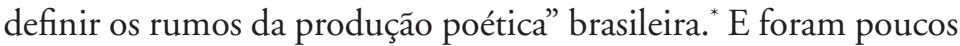
os autores estrangeiros que alcançaram esse grau de influência na formação da literatura brasileira.

Haddad, por sua vez, destaca a "presença física" do poeta francês, que reverbera em repetidas homenagens, que vão desde os pré-parnasianos Carvalho Júnior, Teófilo Dias e Fontoura Xavier, comentados por Antônio Cândido, até o mais recente Vinícius de Morais, passando pela geração parnasiano-simbolista, da qual fez parte, como assinala Haddad, o poeta Pereira da Silva.

Um terceiro aspecto relevante para se dimensionar o papel de Baudelaire no sistema literário brasileiro é o número considerável de traduções e retraduções de sua obra em português. Talvez nenhum outro poeta tenha sido tão traduzido e retraduzido, a ponto de, hoje, dispormos, inclusive, de uma edição de suas obras em português, além de várias ediçôes de poemas das Flores do Mal, algumas integrais.

Assim, Baudelaire, por meio das inúmeras traduções, adaptações, aclimatações, paráfrases e homenagens que recebeu, faz parte do poli-sistema literário brasileiro; e escolher uma das inúmeras versões da tradução do poema "L'invitation au voyage", como as de Guilherme de Almeida, de Ivan Junqueira ou do próprio Haddad, seria um outro modo de se transpor o poeta francês.

Ainda dentro da perspectiva dos poli-sistemas, há outro aspecto a ser considerado: o fato de Les fous de bassans de Anne Hébert ser um romance escrito por uma autora quebequense. Ao identificar a presença de um poeta como Baudelaire no meio de um romance que se passa às margens do Rio São Lourenço, rio que atravessa o Québec, Vera Harvey não se pergunta sobre a hierarquia cultural existente entre o poli-sistema central francês e o poli-sistema peri-
(AMARAL, Glória Carneiro do. Aclimatando Baudelaire. São Paulo: Anna Blume, 1996.)

*(MELlo e SOUSA, Antônio Cândido. Os primeiro baudelairianos. In: A educação pela noite. São Paulo: Ática, 1989: 24.)

(BAUDELAIRE, Charles. As flores do mal. Tradução Jamil Almansour Haddad. Op. cit.:07.) 
férico quebequense. A citação de um poeta que ocupa um lugar de relevo na formação da cultura não só francesa, mas européia, como Baudelaire, não tem o mesmo efeito do que a citação de um poeta local, como seria, por exemplo, o caso do poeta Émile Nelligan. Isto é, apesar de o Québec ter sido colonizado pelos franceses e ser uma região predominantemente francófona, o valor simbólico de um poeta europeu não é o mesmo de um poeta local.

Partindo-se dessa constatação, a substituição do texto de um poeta vindo de um poli-sistema central pelo texto de um poeta de uma cultura periférica é ideologicamente significante, mas, no caso aqui em questão, desconsidera uma variável importante e constitutiva de nosso sistema literário: o lugar que Baudelaire nele ocupa. Nesse sentido, a opção por uma das importantes traduções de Baudelaire feitas no Brasil fosse simbolicamente mais relevante, pois a cultura francesa - e especificamente Baudelaire - ocupa um papel de destaque na formação das literaturas tanto quebequense quanto brasileira.

Enfim, voltando à nossa pergunta - qual é o horizonte de experiência histórica que o tradutor enquanto leitor traz para sua interpretação do original? -; no caso de Vera Harvey, parece ter sido essencialmente sua experiência como leitora que serviu de mediação, pois ela se satisfez com o critério de encontrar algo que lhe fosse familiar; uma vez que, como procurei demonstrar, a escolha de Casimiro de Abreu não se sustenta, nem por uma aproximação estética entre os autores, nem por uma inexistência no sistema literário brasileiro de referências a Baudelaire. Saliento, contudo, que, apesar do apagamento que considero equivocado do texto baudelairiano no romance, Vera Harvey teve o cuidado de expor essa sua escolha em um texto crítico, no qual comenta seu projeto de tradução.

Como assinala André Lefevere, as formas que pode assumir a metaliteratura, como espaço de refração e de canonização de uma obra, incluem não só a tradução, mas os comentários da obras e de suas traduções. Desse modo, ao tornar pública a identificação que fez dos versos de Baudelaire no meio de um romance quebequense, assim como argumentar sobre as motivaçōes que a levaram a devorar Baudelaire transfigurando-o em Casimiro de Abreu, Vera Harvey também cumpre um papel, como diria Lefevere, de "agente

- (VIEIRA, Else. Teorizando e contextualizando a tradução. Op. cit.: 140 .) de continuidade cultural" por contribuir com a discussão sobre os modos de se traduzir ou não, hoje, o poeta francês no Brasil.* 
Outros importantes agentes de continuidade cultural, no que concerne a Baudelaire, são os tradutores, pois, como foi assinalado, há, no Brasil, um conjunto considerável de traduções de suas obras. Em relação a As Flores do Mal, os mais citados costumam ser Guilherme de Almeida, Jamil Almansour Haddad e Ivan Junqueira. O primeiro é responsável por uma seleção pessoal de poemas, publicada originalmente em 1943; o segundo fez a primeira tradução integral das Flores do Mal, em 1957; e o terceiro concluiu a segunda versão completa do livro de Baudelaire, em 1985. Mais recentemente, em 2003, Juremir Machado da Silva publicou uma curiosa seleção de poemas de Baudelaire, intitulada Flores do mal: o amor segundo Charles Baudelaire. Nas quatro publicações, há traduções do poema "L'invitation au voyage". Nas linhas que seguem elaboramos algumas considerações sobre as mesmas.

\section{O poema "L'invitation au voyage"}

O poema "L'invitation au voyage" encontra-se na primeira seção do livro, intitulada "Spleen e Ideal”, e é claramente um dos que se situa na perspectiva da idealidade baudelairiana. Trata-se de um poema sobre a evasão rumo a um mundo mágico, nesse caso exótico e sensual. Essa temática, cara aos românticos, aparece com freqüência em Baudelaire, a ponto de ele ter sido chamado de "Une Bible de l'évasion". " Como assinala Marcel Raymond, o essencial do modo de expressão romântico é ter

a vantagem de devolver à linguagem algumas de suas mais antigas prerrogativas - as mesmas que um Baudelaire tentará utilizar para fazer da poesia uma "magia sugestiva". "Libertar a alma", encontrar novamente o "estado natural", que era, em suma, esta esperança senão a conseqüência de um sonho ancestral semimergulhado no inconsciente, o sonho de um universo mágico...*

No caso de Baudelaire e do poema "L'invitation au voyage", contudo, libertar a alma não leva à busca de um estado natural, é outro o "romantismo" de Baudelaire. Como afirma o próprio poeta no seu artigo "Qu'est-ce que le Romantisme?" do Salon de 1846: "Qui dit romantisme dit art moderne, - c'est-à-dire intimité, spiritualité, couleur, aspiration vers l'infini, exprimées par tous les moyens que contiennent les arts".
"(SELLIER, Philippe. L'évasion. Paris: Bordas, 1971.)

* (RAYMOND, Marcel. De Baudelaire ao Surrealismo. Tradução Fulvia Moretto e Guacira Machado. São Paulo: Edusp, 1997: 14. Grifo do autor.)

* (BAUDELAIRE, Charles. CEuvres. Paris: Gallimard Pléiade, 1951: 602.) 
(FRIEDRICH, Hugo. Estrutura da lírica moderna. Tradução Marise Curioni e Dora Ferreira da Silva. São Paulo: Duas Cidades, 1978: 40)

Hugo Friedrich, ao comentar a estrutura do livro de Baudelaire, assinala que, na primeira parte, trata-se do contraste entre ascensão e queda - "Spleen e Ideal". Nas duas partes seguintes, anunciam-se tentativas de evasão: no mundo externo da metrópole - "Tableaux Parisiens" - e no paraíso da arte - "Le Vin". Essas buscas levam à fascinação do destrutivo - "Les Fleurs du Mal" - e à revolta - "Révolte". Esse processo culmina com uma aspiração rumo ao infinito, a Morte, que aparece no final do poema que encerra As Flores do Mal, "Le Voyage":

Ô Mort, vieux capitaine, il est temps! levons l'ancre! Ce pays nous ennuie, ô Mort! Appareillons! Si le ciel et la mer sont noirs comme de l'encre, Nos coeurs que tu connais sont remplis de rayons!

Verse-nous ton poison pour qu'il nous réconforte! Nous voulons, tant ce feu nous brûle le cerveau, Plonger au fond du gouffre, Enfer ou Ciel, qu'importe? $\mathrm{Au}$ fond de l'Inconnu pour trouver du nouveau!

Assim, "como última tentativa, resta encontrar a tranqüilidade na morte, no absolutamente desconhecido". ${ }^{\text {O }}$ poema "L'Invitation au Voyage" seria um prenúncio da última viagem, um primeiro convite rumo à transcendência final, cuja imagem é de um universo mágico artificial.

O poema se inicia, precisamente, com um convite a uma figura feminina "mon enfant, ma soeur" (seria ela a própria morte?) para que ela venha "Songer à la douceur/ D'aller là-bas vivre ensemble", e, nesse lugar misterioso, que se assemelha a ela e a seus chorosos e traidores olhos, ir "amar e morrer". Lá, livre da dor terrena, seria possível sucumbir a toda uma série de encantos.

Antes, contudo, de apresentar esses encantos, verifica-se, na segunda metade da primeira estrofe, uma comparação entre "les soleils mouillés" e os encantos misteriosos dos "traittres yeux/ brillant à travers leurs larmes". O mistério liga-se, assim, ao brilho ambíguo de um choro causado por uma traição; uma queda desde os céus turvados até o nebuloso e fascinante sofrimento terrestre, lugar possível de evocação de um outro mundo, ideal, sintetizado no dístico, que serve de estribilho, onde se lê:

Là, tout n'est qu'ordre et beauté, Luxe, calme et volupté. 
Note-se que, no primeiro verso do estribilho, inicia-se com a "ordem" seguida pela "beleza”, esta em posição de destaque na rima. E, o segundo verso, após caracterizar esse lugar misterioso como um lugar cheio de luxo e de calma, termina com a "volúpia", ou seja, as imagens que se destacam no estribilho, são as de "beleza" e "volúpia", envolvidas, porém, numa atmosfera calma e ordenada. Pelo modo com estão dispostos, a "ordem" e a "beleza" funcionam como uma espécie de síntese dos elementos que compóem a atmosfera desse universo encantatório, que ganha contornos mais definidos no segundo dístico.

Nas duas estrofes seguintes, tem-se a descrição desse ambiente. Ali desfilam móveis polidos que decoram o quarto, flores de mil odores, ricos telhados decorados, espelhos; um todo que falaria em segredo de seu "esplendor oriental". O lugar privilegiado é o quarto, cercado de fragrâncias, coberto de riquezas exóticas e pelo brilho dos espelhos. Como diz o poeta em "Chambre double", "une chambre qui ressemble à une rêverie".*

$\mathrm{Na}$ última estrofe, são evocados quietos canais e barcos, que vêm do fim do mundo para, sobretudo, saciar todos os desejos daquela que foi convidada a fazer essa voluptuosa viagem. E, enfim, o poente cobre todo aquele universo, que adormece sob "une chaude lumière", sem nenhum retorno ao mundo real. Destaca-se, por fim, o estribilho que sintetiza o clima voluptuoso e sensual que esse mundo mágico sugere e que se faz belo por se encontrar em um ambiente calmo e ordenado.

A estrutura formal do poema, diferentemente dos alexandrinos que dominam a maior parte dos poemas das Flores do Mal, assemelha-se à de uma "chanson": são doze versos em que se intercalam dois pentassílabos, que rimam entre si; e um heptassílabo, que rima com o heptassílabo seguinte, formando a estrutura estrófica AABCCBDDEFFE. Os versos curtos e intercalados dão velocidade - sensualidade - ao texto. $\mathrm{O}$ tom prosaico que domina o poema deve-se a uma escolha vocabular simples; e mesmo as imagens mais grandiloqüentes, como "soleils mouillés", "ciels brouillés", "riches plafonds", são construídas com um léxico bastante despojado. $\mathrm{O}$ convite parece, pois, uma confissão sussurrada na intimidade.

Esta brevíssima apresentação do texto tem como intuito apenas relembrar ao leitor os elementos que estruturam o poema para que ele, assim, disponha de mais instrumentos para compreender as minhas considerações sobre a tradução.

* (BAudelaire, C. CEuvres. Op. cit.: 277 .) 
(BAUDELAIRE, C. As flores das flores do mal. Rio de Janeiro: Ediouro, s.d.:15.)

\section{Algumas considerações sobre traduções de "L'invitation au Voyage"}

Não se trata aqui de fazer uma análise detalhada de cada uma das traduções, destaco apenas as traduções do estribilho, por ser ele, como procurei demonstrar, uma espécie de síntese do poema. Além disso, creio que as traduções do estribilho parecem ilustrar as abordagens adotadas pelos tradutores acima já mencionados: Guilherme de Almeida, Jamil Mansour Haddad, Ivan Junqueira e Juremir Machado da Silva.

O primeiro dos tradutores em questão, Guilherme de Almeida, ao comentar sua proposta de tradução, define seu trabalho como uma recriação. E, por se tratar, segundo ele, do resultado de um processo lento e contínuo de memorização dos textos, eles acabariam ressurgindo em português:

À força de dizê-los e redizê-los, citá-los e recitá-los, acabei por me surpreender ouvindo-os de mim mesmo na minha língua mesma. E, por isso, com seu ritmo nativo intacto, com seu espírito inato incólume.

Ainda que soe hoje algo ingênuo o teor de suas últimas considerações - "ritmo nativo intacto", "espírito inato incólume" -, estas indicam seu propósito de aproximar-se formalmente e retoricamente do texto baudelairiano. Dessa sua relação orgânica com os textos surgiu, para o referido estribilho, a seguinte tradução:

\section{Lá, tudo é ordem e nitidez, Là, tout n'est qu'ordre et beauté, Luxo, calma e languidez Luxe, calme et volupté}

Dessa maneira, o "belo" torna-se "nítido" e a "voluptuosidade" perde um pouco de ímpeto em seu sinônimo "languidez", ainda que a imagem retome a sensualidade sugerida. Esse apagamento da "beleza", exigido pelas escolhas da rima, produz uma oposição entre o primeiro verso, em que se destaca apenas a idéia de ordem, e o segundo, marcado pelo luxo e a languidez. Assim, ao substituir "beleza" por "nitidez", Guilherme de Almeida produz um estribilho mais frio, mais distante da "chaude lumière" que invade o final da última estrofe.

Haddad, por sua vez, revela sua postura tradutória ao afirmar:

$\mathrm{O}$ vezo da tradução de Baudelaire pode ser entre nós levado à conta do triunfo da estética parnasiana. Só mesmo uma escola poética 
desta ordem, levando longe o sonho de apuro da linguagem e perfeição técnica, pode fazer da tradução de poemas um exercício realmente valioso."

Desse modo, assim como Guilherme de Almeida, na solução que propõe, Haddad destaca mais as figuras da ordem e da calma, como se pode notar:

\section{Lá tudo é belo e se ordena - Luxo volúpia serena}

\section{Là, tout n'est qu'ordre et beauté Luxe, calme et volupté}

Como afirma o próprio verso, Haddad ordena o discurso. Ele modifica a hierarquia dos elementos: no primeiro verso, é o belo que se ordena, a "ordem" passa a ser o predicado verbal da beleza; no segundo verso, algo semelhante ocorre, pois, na origem, "luxo, calma e volúpia" tinham o mesmo estatuto enumerativo, mas, na tradução, "volúpia serena” passou a ser aposto de "luxo", assumindo, dessa forma, um caráter explicativo. Na imagem criada por Haddad ,predomina ainda mais a "ordem", e a "volúpia”, por sua vez, perde força e destaque, pois, além de ser serena (oxímoro inexistente em Baudelaire), ela reduz-se a um aposto.

Em Ivan Junqueira, tradutor também fiel ao "apuro da linguagem e à perfeição técnica”, predomina uma vez mais a ordem, pintada com cores ainda mais fortes:

\section{Lá, tudo é paz e rigor, Luxo, beleza e langor. \\ Là, tout n'est qu'ordre et beauté Luxe, calme et volupté}

Aquilo que era "ordem" passa à esfera do "rigor", modulação que acrescenta rigidez à organização; parece-me que, no poema de Baudelaire, a ordem aproxima-se da harmonia e da quietude e produz o que Richard chama de "un état de paix ondulatoire." Assim como em Guilherme de Almeida, Junqueira introduz uma oposição entre as imagens, inexistente no original. De um lado "paz e rigor", do outro "luxo, beleza e langor". Ainda que os sinônimos sejam próximos, o fato de modificar a ordem, e, sobretudo, tirar o destaque dado à rima "beautél volupté" faz com que o poema adquira um tom mais severo.

A quarta tradução, proposta por Juremir Machado da Silva, é precedida de um breve prefácio, intitulado "Reescandalizar Baudelaire ou como ser fielmente infiel”. Silva traça ligeiros comentários sobre as três traduções aqui comentadas. Ele considera as es-
(BAUDELAIRE, C. As flores do mal. Tradução Jamil Almansour Haddad. Op. cit.: 14.)
(RICHARD, Jean-Pierre. Poésie et profondeur. Paris: Seuil, 1995: 11.) 
(BAUDELAIRE, C. Flores do mal: o amor segundo Charles Baudelaire. Tradução Juremir Machado da Silva. Porto Alegre: Sulina, 2003:5.)

(PERRONE-MOISES, Leila. Altas literaturas. São Paulo: Cia das Letras, 2003: 14.) colhas de Haddad mais "pudicas" em situações de ambigüidade e Ivan Junqueira "mais frio, menos intenso, mais técnico". Quanto às traduçôes de Almeida, contenta-se em chamá-las de "pessoais". Para suas próprias traduçôes, tem como critérios "exclusivamente, a paixão e o caos" e estas, em resposta às traduçõos anteriores, estão "mais fascinadas pelo vulgar do que pelo rebuscado". . Essa sua postura leva-o a traduzir o estribilho da seguinte forma:

\section{Lá, só há beleza e felicidade, Là, tout n'est qu’ordre et beauté \\ Luxo, calma e sensualidade. Luxe, calme et volupté}

Com efeito, Silva produz a mais prosaica das quatro traduções. O destaque que dá à paixão leva-o ao apagamento da idéia de ordem, que se reflete, também, na quebra constante da isometria. A paixão e o caos propostos por Silva esbarram, contudo, no pudor da rima. Em suas traduções, procura manter os mesmos esquemas rímicos encontrados em Baudelaire, ainda que isso acarrete transformações vocabulares importantes. Assim, a liberdade que adquire ao afirmar que: "quis, num gesto de heresia total, dar-lhe [a Baudelaire] um pouco do ar de nosso tempo, frívolo, pós-moderno, efêmero, obsceno", desestabiliza mais retoricamente do que textualmente as propostas tradutórias anteriores; uma vez que fica a meio caminho entre um Baudelaire em prosa, carregado pela força de suas imagens e, por que não, pelo andamento de sua sintaxe, e o Baudelaire lapidador do verso clássico. Enfim, mesmo que seja tomada por uma súbita "felicidade" e desapareça das imagens, a "ordem" resiste desajeitada na rima.

\section{Considerações finais}

Leila Perrone-Moisés destaca que, para muitos escritores, a tradução é "uma forma privilegiada de crítica", um "trabalho seletivo de desmontagem e remontagem do texto original". "Nas traduções aqui apresentadas, além da longamente comentada desmontagem proposta por Harvey, é possível notar que os processos são todos orientados por princípios estéticos. A tradição da tradução poética no Brasil, como assinala com precisão Haddad, é dominada por tendências de inspiração parnasiana ou senão formalistas. A força dessa tradição é tamanha que, mesmo o mais "caótico", "frívolo" e "pós-moderno" tradutor não consegue desvencilhar-se completamente de suas rédeas. 
Goethe identifica três momentos históricos para a tradução poética. Em um primeiro momento da história da recepção de uma obra, proceder-se-ia a uma tradução em prosa, que "apresenta o estrangeiro à nossa maneira". Num segundo momento, haveria uma vontade de "transposição para as condições do estrangeiro", mas apenas "para se apropriar do sentido desconhecido e constituí-lo com sentido próprio", o que consistiria numa atitude "parodística". Enfim, chegar-se-ia a uma tradução em que se procurasse o outro, o que levaria a uma estrangeirização da língua de chegada; essa tradução, no caso de Goethe, levaria à busca de uma literalidade, que ele chama de "identidade".

Ainda que seja bastante contestável o caráter evolutivo e determinista da classificação proposta por Goethe, ela nos leva a pensar sobre o momento histórico das traduções. No caso das traduções de Baudelaire, pode-se pensar a escolha de Vera Harvey como uma tradução que apresenta um Baudelaire "à nossa maneira”, e os primeiros baudelairianos estudados por Antônio Candido seriam, em certo sentido, parodísticos. No que concerne aos três primeiros tradutores aqui comentados e à reação de Juremir Machado de Silva, esta última sugere uma espécie de esgotamento de um determinado modelo e o surgimento de uma nova proposta de tradução, ou seja, contamos hoje, com um conjunto considerável de traduçôes dos poemas de Baudelaire que, muitas vezes, em detrimento das imagens, fixaram-se nos aspectos formais, produzindo um Baudelaire mais rigoroso e frio, de índole parnasiana. Com sua atitude irreverente, Silva tenta outra via que, com seu ímpeto pioneiro, chega de forma ainda rude e desajeitada, mas abre a primeira picada numa senda ainda inexplorada no Brasil.

Enfim, é possível dizer que os três renomados tradutores de Baudelaire aqui estudados aproximam-se bastante dos primeiros baudelairianos, que, por sua vez, conforme Antônio Candido, foram "uma espécie de pré-parnasianos, sobretudo na medida em que aprenderam com seu inspirador o cuidado formal, o amor pelas imagens raras, a recuperação do soneto e das formas fixas [...] mas refugaram ou não sentiram bem a coragem do prosaísmo e dos torneios coloquiais". "Talvez agora, quase 150 anos depois de sua primeira recepção, estejamos mais próximos de ensaios que arrisquem uma outra maneira de traduzir, mais prosaica e coloquial, as Flores do Mal no Brasil.
* (GOETHE, Johann Wolfgang von. "Três trechos sobre tradução". Em: HEIDERMANN, W. Clássicos da teoria da tradução 1 : alemão-português. Florianópolis: UFSC/ NUPLITT, 2001: 19ss.)

" (MELLO E SOUSA, Antônio Cândido. "Os primeiro baudelarianos". A educação pela noite. São Paulo: Ática, 1989:38.) 


\section{Álvaro Faleiros}

Álvaro Faleiros é poeta e tradutor. Atualmente é professor na Universidade de Brasília. Publicou, entre outras, as seguintes traduções: O Bestiário de Apollinaire (Iluminuras, 1995), Latitudes: 9 poetas do Québec (Nankin, 1997) e Caligramas, de Apollinaire (Ateliê, no prelo). Tem artigos e capítulos de livros sobre tradução poética publicados no Brasil, na França e no Canadá.

\section{Resumo}

Palavras-chave: Baudelaire Ao comentar sua tradução do romance Les fous de bassan de Anne Hébert, Vera de Azambuja Harvey verifica que se achavam inseridos alguns versos do poema "L'invitation au voyage" de Baudelaire, traduzidos em seu texto por versos de Casimiro de Abreu. Nosso objetivo é discutir o que essa escolha acarreta. A partir dessas considerações, examinamos aspectos suscitados por algumas traduções deste poema no Brasil.

Key words: Baudelaire; translation; french poetry.

Mots-clés: Baudelaire; traduction; poésie française.

\section{Abstract}

In the commentaries about her translation of the Anne Hébert's romance Les fous de bassan, Vera de Azambuja Harvey discusses her finding in this romance of some verses from the Baudelaire's poem "L'invitation au voyage"; replaced in her translation by Casimiro de Abreu's verses. Our aim is to discuss what's involving in this choice. Using these considerations we examine aspects concerning some translations of this poem in Brazil.

\section{Résumé}

Dans le commentaire à sa traduction du roman Les fous de bassan d'Anne Hébert, Vera de Azambuja Harvey discute la présence quelques vers du poème "L'invitation au voyage" de Baudelaire, qu'elle traduit par des vers de Casimiro de Abreu. Notre objectif est de discuter les implications d'un tel choix. Partant de ces considérations, nous examinons des aspects suscités par quelques traductions de ce poème au Brésil. 